\section{Apoptosis of leukocytes triggered by acute DNA damage promotes lymphoma formation}

\author{
Verena Labi, ${ }^{1}$ Miriam Erlacher, ${ }^{1,2}$ \\ Gerhard Krumschnabel, ${ }^{1}$ Claudia Manzl, ${ }^{1}$ \\ Alexandar Tzankov, ${ }^{3}$ Josephina Pinon, ${ }^{4}$ \\ Alexander Egle, ${ }^{4}$ and Andreas Villunger ${ }^{1,5}$
}

\begin{abstract}
${ }^{1}$ Division of Developmental Immunology, Biocenter, Innsbruck Medical University, Innsbruck 6020, Austria; ${ }^{2}$ Department of Pediatrics and Adolescent Medicine, Division of Pediatric Hematology and Oncology, University Hospital of Freiburg, Freiburg 79106, Germany; ${ }^{3}$ Institute for Pathology, University of Basel, Basel 4031, Switzerland; ${ }^{4}$ Laboratory for Immunological and Molecular Cancer Research, Third Medical Department, Paracelsus Medical University, Salzburg 5020, Austria
\end{abstract}

Apoptosis triggered by p53 upon DNA damage secures removal of cells with compromised genomes, and is thought to prevent tumorigenesis. In contrast, we provide evidence that p53-induced apoptosis can actively drive tumor formation. Mice defective in p53-induced apoptosis due to loss of its proapoptotic target gene, puma, resist $\gamma$-irradiation (IR)-induced lymphomagenesis. In wildtype animals, repeated irradiation injury-induced expansion of hematopoietic stem/progenitor cells (HSCs) leads to lymphoma formation. Puma ${ }^{-/-}$HSCs, protected from IR-induced cell death, show reduced compensatory proliferation and replication stress-associated DNA damage, and fail to form thymic lymphomas, demonstrating that the maintenance of stem/progenitor cell homeostasis is critical to prevent IR-induced tumorigenesis.

Supplemental material is available at http://www.genesdev.org.

Received April 22, 2010; revised version accepted June 15, 2010.

Tumorigenesis is a multistep process that can be initiated or accelerated by genetic lesions caused by DNA damage. These oncogenic events facilitate neoplastic transformation by the selection of disease-initiating "cancerous stem cells" against anti-oncogenic mechanisms, such as apoptosis, cellular senescence, and/or maintenance of genomic stability (Rossi et al. 2008). All of these defense mechanisms depend to a significant extent on the tumor suppressor $p 53$, the gene most frequently inactivated in human cancer (Vousden and Lane 2007). p53's ability to promote apoptosis in response to DNA damage is considered critical for tumor suppression, but induction of cellular senescence or the maintenance of genomic integrity is considered to contribute (Vousden and Lane 2007). Apoptosis induced in response to DNA damage is medi-

[Keywords: Apoptosis; p53; BH3-only proteins; stem cells; $\gamma$-irradiation; cancer]

${ }^{5}$ Corresponding author.

E-MAIL andreas.villunger@i-med.ac.at; FAX 43-512-507-2867.

Article is online at http://www.genesdev.org/cgi/doi/10.1101/gad.1940210. ated mainly by the p53 target gene puma, but other members of the "BH3-only" subgroup of $\mathrm{Bcl} 2$ proteins, including bim and noxa, can contribute (Erlacher et al. 2005; Michalak et al. 2008). Puma and Bim show nonredundant functions in lymphocyte apoptosis; e.g., in cell death induced by cytokine deprivation, glucocorticoids, and DNA damage (Erlacher et al. 2006). Notably, thymocytes and mature $\mathrm{T}$ and $\mathrm{B}$ cells from bim ${ }^{-1-}$ puma $^{-1-}$ double-deficient mice resist $\gamma$-irradiation (IR)induced apoptosis more potently than lymphocytes from puma ${ }^{-1-}$ nox $a^{-1-}$ mice, although bim, in contrast to noxa, is not a direct p53 target gene (Erlacher et al. 2006; Michalak et al. 2008). Loss of BH3-only proteins, most frequently Bim, has been documented in human cancer, and is associated with impaired drug responsiveness and/ or poor prognosis (Frenzel et al. 2009). In line with a critical role for $\mathrm{BH} 3$-only protein-mediated apoptosis in tumor suppression, loss of Puma or Bim accelerates oncogene-driven tumorigenesis in mice (Egle et al. 2004; Garrison et al. 2008; Michalak et al. 2009). Here, we investigated the contribution of these two $\mathrm{BH} 3$-only proteins to tumor suppression in response to DNA damage in gene-ablated mice, and provide evidence that p53-induced apoptosis, executed via activation of Puma, can promote IR-induced lymphomagenesis.

\section{Results and Discussion}

\section{Loss of puma prevents IR-induced thymic lymphoma formation}

Exposure of mice to repeated low-dose IR drives lymphoma formation through a mechanism suppressed by p53 (Kaplan and Brown 1952; Kemp et al. 1994). Wholebody IR of mice induced the DNA damage response regulators p53, p21, Puma (but not Bim), and $\gamma$-phosphorylated H2AX, as well as hallmarks of apoptosis such as activated caspase- 3 and cleaved PARP in thymocytes. Interestingly, H2AX was still found phosphorylated in puma $^{-/-}$or $p 53^{-/-}$cells $24 \mathrm{~h}$ after irradiation, indicating that damaged cells are still present in these but successfully cleared in wild-type mice (Supplemental Fig. 1A). As expected (Macleod et al. 1995; Michalak et al. 2008), p53deficient thymocytes failed to induce p21 or Puma, or to fully process caspase-3. Puma ${ }^{-/-}$cells also poorly induced p21, despite normal stabilization of p53-a phenomenon not observed when recapitulated ex vivo (Supplemental Fig. 1A,B), suggesting that this effect was not cell-autonomous. Nonetheless, puma ${ }^{-/-}$thymocytes halted their cell cycle as efficiently as wild-type cells, evidenced by the fast drop of phospho-histone 3 (pH3)-positive mitotic cells. In addition, the percentage of thymocytes that incorporated BrdU into DNA following IR was reduced in wildtype, bim ${ }^{-/-}$, and puma $a^{-/-}$mice to a similar extent, suggesting that these mouse mutants show a largely normal DNA damage response. Consistent with previous observations, $p 53^{-/-}$cells failed to arrest in G1 (Brugarolas et al. 1995), but showed a largely normal G2 arrest (Supplemental Fig. 2A,B).

The numbers of $\mathrm{CD}^{+} 8^{+}$(DP) thymocytes in wild-type mice dropped to $\sim 10 \%$ of untreated controls within $24 \mathrm{~h}$ after a single dose of IR, and mobilization of progenitors replenished the organ before the next irradiation cycle. 
Depletion of DP thymocytes after IR was mildly delayed in $\mathrm{bim}^{-1-}$ mice, consistent with our previous finding (Erlacher et al. 2005), but cell numbers also dropped to $\sim 10 \%$ on day 3 post-IR. Strikingly, thymic cellularity never fell below 50\% in $\gamma$-irradiated mice lacking Puma or p53 (Fig. 1A). Thymocyte numbers rebounded in mice of all genotypes prior to subsequent irradiation. Together, these observations indicate that puma ${ }^{-/-}$thymocytes resist IR-induced apoptosis nearly as potently as $p 53^{-/-}$ones.

IR-triggered cell death was followed by a proliferative burst in the thymi of wild-type mice, peaking at day 3 after treatment, indicating massive mobilization of progenitors from the bone marrow and compensatory proliferation within the thymus (Fig. 1B; Supplemental Fig.
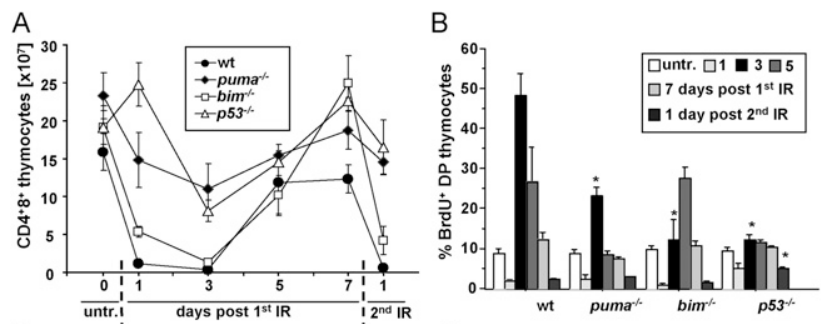

C

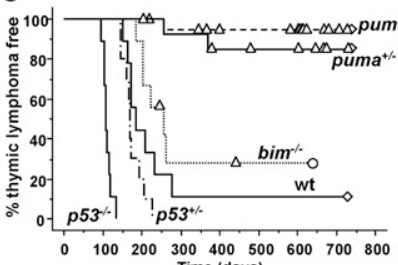

D

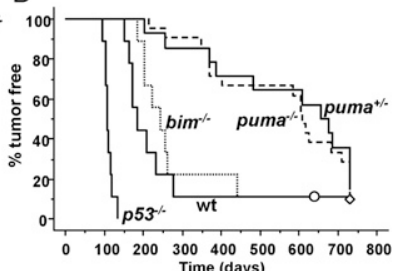

Figure 1. Loss of Puma delays IR-induced lymphomagenesis. Wildtype, puma $a^{-/-}$, and $p 53^{-/-}$mice $4-6 \mathrm{wk}$ of age were exposed to $1.75 \mathrm{~Gy}$ of whole-body IR, and were sacrificed at the indicated time points. $(A)$ The number of $\mathrm{CD}^{+} 8^{+}$thymocytes was quantified by cell counting and cell surface staining, followed by flow cytometric analysis. Each data point represents the mean \pm SEM of three to six animals per genotype and time point. Statistically significant differences in cell number were observed between wild-type versus $\mathrm{puma}^{-/-}$mice on days 1 and 3 after the first IR and day 1 after the second $\operatorname{IR}(P<0.025)$; between wild-type versus bim $^{-1-}$ mice on day $1(P=0.005)$; and between wild-type and $p 53^{-1-}$ mice on days 1,3 , and 7 after the first IR and day 1 after the second IR $(P<0.014)$. Untreated puma ${ }^{-1-}$ mice also showed increased cellularity compared with the other genotypes $(P<$ 0.001). (B) Mice of the indicated genotypes were exposed to $1.75 \mathrm{~Gy}$ of IR at the indicated time points and were injected i.p. with $\operatorname{BrdU} 4 \mathrm{~h}$ before sacrifice. The percentage of cycling $\mathrm{CD} 4^{+} 8^{+}$thymocytes was defined by combined staining of cell surface markers, followed by intracellular staining of BrdU, followed by flow cytometric analysis. Data points represent the mean \pm SEM of three to six animals per genotype and time point. Statistically significant differences in BrdU uptake were observed between wild-type versus puma ${ }^{-/-}$mice on day $3(P=0.003)$, wild-type versus $b^{-/-}$on day $3(P<0.015)$, and wildtype versus $p 53^{-/-}$at day 3 after the first IR and day 1 after the second IR $(P<0.02)$. Untreated controls were not different across genotypes. Cohorts of wild-type $(n=16)$, puma ${ }^{+-}(n=12)$, puma $^{-/-}(n=20)$, bim $^{-1-}(n=9)$, and $p 53^{-1-}(n=9)$ mice were subjected to fractionated IR (four times at1.75 Gy) at weekly intervals, starting at 4 wk of age, and were monitored for the development of tumors up to $730 \mathrm{~d}$. (C) Kaplan-Meier analysis of thymic lymphoma-free survival of mice of the indicated genotypes. $(D)$ Tumor-free survival of cohorts of mice shown in $C$. Mean survival in days \pm SE: $201 \pm 9$ for wild type versus $570 \pm 52$ for puma ${ }^{+/-}$versus $558 \pm 38$ for puma pum $^{-/-}$(Fig. 2A,B); $P<0.0001$. Circles represent mice still alive, triangles represent mice that developed tumors distinct from thymic lymphomas, and diamonds represent mice that were tumor-free at the end of the observation period; i.e., $730 \mathrm{~d}$.
2B). Bim deficiency caused a delayed proliferative burst, reaching its maximum at day 5 post-IR, in correlation with the delayed thymocyte depletion (Fig. 1A). In contrast, mice lacking Puma or p53 showed a strongly reduced proliferative response (Fig. 1B).

Following cohorts of mice treated with four weekly doses of IR, we observed that loss of p53 accelerated thymic lymphoma formation, confirming a previous study (Kemp et al. 1994). Loss of Bim had no effect on tumor latency $(P=0.17)$. Remarkably, loss of one or both alleles of puma abrogated thymic lymphoma formation induced by IR (Fig. 1C). Long-term surveillance and histopathological assessment revealed that, very late in follow-up, a portion of puma $^{+/-}$and puma ${ }^{-/-}$mice developed different malignancies, including high-grade and low-grade lymphomas, carcinomas, and sarcomas, but others were still without signs of pathology when analyzed after $730 \mathrm{~d}$ (Fig. 1D; Supplemental Fig. 3). Notably, in untreated animals, loss of Puma did not reduce spontaneous tumorigenesis or extend lifespan, suggesting that irradiation injury is necessary to unmask this unexpected tumor-suppressive process in puma $^{-1-}$ mice (Supplemental Table1; Supplemental Fig. 3).

\section{Lack of T-cell apoptosis upon DNA damage fails to prevent lymphomagenesis}

According to the "initiator-promoter" model of tumor formation, these observations suggest that enhanced proliferation of stem/progenitor cells triggered by apoptosis of differentiated cells and subsequent creation of space acts as a strong promoter of tumor formation by expanding progenitors that carry oncogenic lesions induced by DNA damage. If leukocyte depletion in the thymus was critical for lymphomagenesis, overexpression of $\mathrm{Bcl}-\mathrm{x}_{\mathrm{L}}$ in the T-cell lineage should prevent tumorigenesis after IR. Similarly, Puma deficiency should fail to delay tumor formation triggered by DNA damage in radio-resistant tissues lacking a compensatory proliferative response. The latter was addressed using intramuscular (i.m.) injection of the hydrocarbon 3-Methylcholanthrene (3-MC), a carcinogen that causes DNA damage by forming bulky adducts, promoting formation of fibrosarcomas, suppressed by p53 (Garcia-Cao et al. 2002). Fibrosarcomas formed within $7 \mathrm{mo}$ in wild-type and $\mathrm{puma}^{-/-}$mice alike (Fig. 2A), suggesting that the protection from tumorigenesis observed with loss of Puma needs tissue depletion and the generation of space. In contrast, overexpression of Bcl- $x_{\mathrm{L}}$ in thymocytes and T cells (Chao et al. 1995) did not significantly delay the formation of thymic lymphomas in lck-bcl-x transgenic mice exposed to IR (Fig. 2B). This was surprising, given that overexpression of $\mathrm{Bcl}-\mathrm{x}_{\mathrm{L}}$ prevented cell death as well as compensatory proliferation in the thymus after IR as efficiently as loss of Puma (Fig. 2C,D; Supplemental Fig. 4A). Together, this suggested that generation of space by T-cell apoptosis cannot be the sole critical factor driving tumorigenesis, and that the "tumor-initiating cell" - kept in check by the absence of cell death in puma ${ }^{-/-}$mice-must be either a very early thymic progenitor in which the lck promoter is still silent, or an even less differentiated hematopoietic progenitor. This idea is consistent with the observation that vav-bcl-2 transgenic mice overexpressing Bcl-2 in all hematopoietic cells, including hematopoietic stem/progenitor cells (HSCs), fail to develop thymic lymphomas upon IR (Michalak et al. 2010), and the observation that 

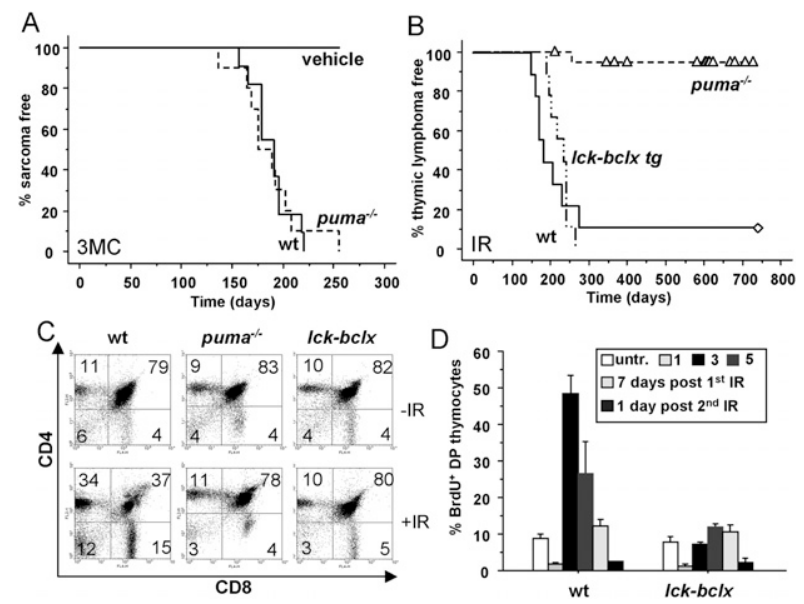

Figure 2. Lack of protection from tumorigenesis by loss of Puma in the absence of tissue depletion or by overexpression of Bcl-x in the T-lymphoid linage. $(A)$ Cohorts of adult wild-type $(n=10)$ and puma $^{-/-}$ $(n=11)$ mice received a single injection of 3-MC or vehicle (seven mice per genotype) i.m. in the gluteus. Local tumor growth was monitored over $255 \mathrm{~d}$, and animals were sacrificed when tumors reached $\geq 1 \mathrm{~cm}$ in size. $(B)$ Cohorts of $l c k-b c l-x \operatorname{tg}(n=9)$ mice were monitored for tumorigenesis triggered by fractionated IR, and were monitored for the development of thymic lymphomas over time. Triangles represent mice that developed tumors distinct from thymic lymphomas, and diamonds represent mice that were tumor-free at $730 \mathrm{~d}$. (C) Wild-type, puma $^{-1-}$, and lck-bcl-x tg mice were exposed to a single dose of IR (1.75 Gy). Animals were sacrificed after $24 \mathrm{~h}$, and thymic single-cell suspensions were counted and stained for cell surface markers, followed by flow cytometric analysis. Representative dot blots from three independent experiments and animals per genotype defining the changes in the percentages of $\mathrm{CD} 4^{+} 8^{+}$thymocytes upon IR are shown. (D) Quantification of BrdU incorporation and S-phase activity in $l c k-b c l-x$ tg transgenic mice, performed as described in Figure 1B. Statistically significant differences in BrdU uptake were observed between wild-type versus $b c l-x \operatorname{tg}$ mice on day $3(P=0.007)$.

IR-induced tumorigenesis can be suppressed by the transfer of healthy bone marrow into irradiated recipients or bone marrow shielding (Kominami and Niwa 2006). Therefore, we reasoned that IR damage in stem/progenitor cells selects for a pool of cells carrying oncogenic lesions that provide a proliferative advantage, acquiring additional alterations during differentiation and expansion. This may facilitate transformation most frequently in the thymus, presumably due to the high risk for chromosomal translocations arising during the recombination of T-cell receptors (Liao and Van Dyke 1999). Alternatively, most stem/progenitor cells actually die after IR, and the few survivors are forced to replenish the periphery to avoid fatal hypoplasia, thereby accumulating further DNA damage due to replication stress. Such primed precancerous cells are usually cleared by a functional DNA damage response. This model is consistent with the high frequency of p53 inactivation observed in IR-induced thymic lymphomas from wild-type and $p 53^{+/-}$mice (Brathwaite et al. 1992; Kemp et al. 1994), and a recent study describing that irradiation strongly selects for p53-deficient hematopoietic progenitors (Marusyk et al. 2010).

\section{Lack of stem cell apoptosis and compensatory proliferation in irradiated $\mathrm{puma}^{-/-}$mice}

We monitored bone marrow dynamics upon IR and analyzed the HSC-containing $\mathrm{Iin}^{-} \mathrm{Sca}-\mathrm{1}^{+} \mathrm{c}-\mathrm{kit}{ }^{+}$(LSK) population, as well as the $\left(\mathrm{lin}^{-} \mathrm{Scal}^{+} \mathrm{ckit}^{+} \mathrm{CD} 48^{-} \mathrm{CD} 150^{-}\right)$multipotent progentiors (MPPs) and $\left(\mathrm{lin}^{-} \mathrm{Scal}^{+} \mathrm{ckit}^{+} \mathrm{CD} 48^{-} \mathrm{CD} 150^{+}\right)$fraction, highly enriched for long-term HSCs (LT-HSCs). The percentages and numbers of LSK cells in wild-type, bim, and lck-bcl-x tg mice-the latter being functionally wild type in the bone marrow-dropped significantly upon IR of animals with a single dose of $1.75 \mathrm{~Gy}$, but, in contrast to thymic cellularity, failed to recover prior to subsequent irradiation (Fig. 3A). The percentages and numbers of LSK cells in puma ${ }^{-/-}$mice did not change, or, in the case of $p 53^{-1-}$ mice, even transiently increased, possibly due to impaired p21 activation, demonstrating resistance of these cells to IR-induced apoptosis (Fig. 3B; Supplemental Fig. 4B,C). Consistent with their relative radio resistance, LTHSC numbers declined more slowly than MPP numbers in wild-type or bim ${ }^{-/-}$, but were less affected in $\mathrm{puma}^{+/-}$ mice (data not shown), or were unaffected in puma ${ }^{-/-}$or p53 $3^{-/-}$mice (Fig. 3C,D; Supplemental Fig. 4D,E). Apoptosis resistance of Puma- or p53-deficient HSCs was cellautonomous, as demonstrated on FACS-sorted stem cells subjected to IR ex vivo (Supplemental Fig. 5A). Moreover, loss of Puma preserved the clonal fitness of irradiated LTHSCs, as shown by their better performance in a competitive reconstitution assay using bone marrow from Ly5.1 ${ }^{+}$ wild-type and Ly5. $2^{+}$wild-type or puma $a^{-1-}$ mice harvested $24 \mathrm{~h}$ after irradiation (Supplemental Fig. 5B). These findings are well in line with the reported role for puma in IRtriggered stem/progenitor cell apoptosis (Wu et al. 2005; Shao et al. 2010; Yu et al. 2010). One study also speculated that IR-driven tumor formation may be reduced in puma ${ }^{-1-}$ mice, but experimental proof was not provided, and all relevant controls died from bone marrow failure or gastrointestinal syndrome shortly after high-dose IR (Yu et al. 2010).

Consistent with a strong demand for compensatory proliferation and HSC mobilization due to apoptotic cell loss of differentiated leukocytes, surviving MPPs showed

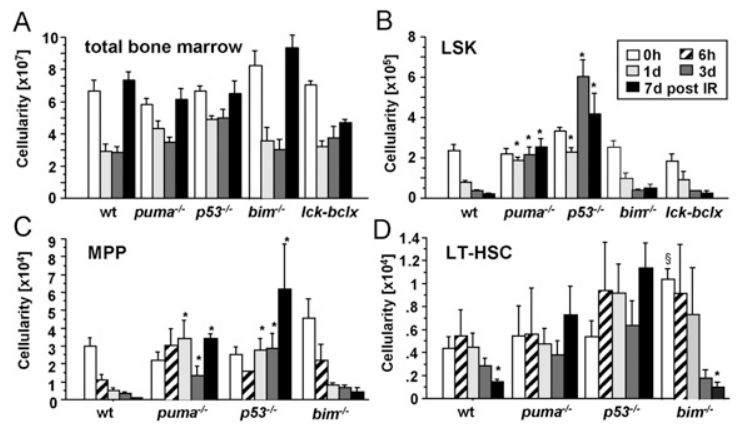

Figure 3. Loss of Puma prevents stem cell apoptosis upon IR. $(A)$ Cellularity of both femora and tibiae was assessed in mice of the indicated genotypes after exposure to a single dose of IR. $(B-D)$ Cell counting and staining with cell surface marker-specific antibodies were used to identify and enumerate the different stem cell populations. Bars represent mean \pm SEM of three to six animals per genotype and time point from three independent experiments. $\left({ }^{*}\right)$ LSK cell numbers were significantly different between wild-type or bim $^{-/-}$ versus $\mathrm{puma}^{-/-}(P<0.0002)$ or $p 53^{-/-}$mice $(P<0.0014)$ at all time points analyzed after IR; MPP numbers were different between wildtype or bim ${ }^{-1-}$ versus puma ${ }^{-/-}(P<0.04)$ or $p 53^{-1-}$ mice $(P<0.035)$ at days 1,3 , and 7 after IR; LT-HSC numbers were different between wildtype or bim $^{-/-}$versus puma $a^{-/-}(P<0.038)$ or $p 53^{-/-}$mice $(P<0.003)$ at day 7 after IR. (§) In untreated mice, LT-HSC numbers were different between $\mathrm{bim}^{-}-$and all other genotypes $(P<0.05)$. 
an approximately sevenfold increase in S-phase activity in BrdU-labeling experiments at days 3 and 7 after IR, compared with untreated controls $(P<0.03)$, while LTHSCs displayed an approximately twofold increase (Fig. 4A; Supplemental Fig. 6). In the absence of Puma or p53, however, S-phase activity was significantly less increased $(P<0.04)$. Noteworthy, this "snapshot analysis" failed to reveal proliferation differences in the LSK population; however, long-term BrdU loading of HSC and subsequent pulse-chase analysis (Wilson et al. 2008) of animals exposed to one or two cycles of IR confirmed the strongly reduced proliferative response - indicated by reduced loss of BrdU label-in puma ${ }^{-/-}$mice $(P<0.01)$ in all stem/ progenitor cell populations analyzed (Fig. 4B; Supplemental Fig. 7). Ki67 staining and flow cytometric analysis of stem/progenitor cell subsets before and after IR confirmed a significant increase $(P<0.03)$ in stem cell mobilization out of G0 in wild-type mice compared with

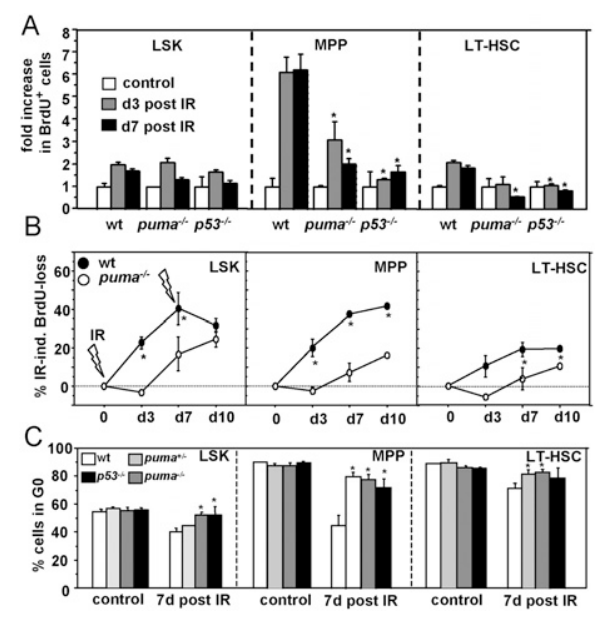

Figure 4. Loss of Puma prevents compensatory proliferation of stem cells upon DNA damage. (A) To compare the rates of proliferation in different stem cell populations, the mice of the indicated genotpyes were exposed to IR, and, on days 3 and 7, were injected i.p. with a single dose of BrdU. Four hours later, mice were sacrificed, and the percentage of $\mathrm{BrdU}^{+}$cells was assessed by flow cytometry in the individual stem cell subsets or total bone marrow. The relative increase in proliferation $\left(\mathrm{BrdU}^{+}\right.$cells) in relation to untreated controls was calculated by using the following equation: (IR-induced proliferation percent - spontaneous proliferation percent $) /(100$ - spontaneous proliferation percent). Bars represent fold induction of $\mathrm{BrdU}^{+}$ cycling cells as mean \pm SEM of three to four animals per genotype and three independent experiments. $\left.{ }^{*}\right)$ Significant differences in BrdU uptake were observed between wild-type and puma $^{-/-}$or $p 53^{-/-}$MPP $(P<0.03)$ and LT-HSC $(P<0.01)$ subsets at days 3 or 7 post-IR. $(B)$ Mice were fed BrdU in drinking water for $12 \mathrm{~d}$, yielding between $70 \%$ and $90 \%$ of labeling efficiency in both genotypes alike. Then mice were exposed to $1.75 \mathrm{~Gy}$ IR at days 0 and 7 . The percentage of BrdU ${ }^{+}$stem cell subsets was assessed by flow cytometry. IR-induced loss of BrdU as an indirect measure of proliferation was calculated by subtracting the percentage of $\mathrm{BrdU}^{+}$cells of mice pre-exposed to IR from the percentage of $\mathrm{BrdU}^{+}$cells in control animals. Symbols represent mean \pm SEM of three to four animals per genotype and time point. Spontaneous BrdU loss was not different between genotypes $(P>$ 0.78). $\left.{ }^{*}\right)$ BrdU loss was significantly different at all time points after IR in MPP $(P<0.014)$ and LSK $(P<0.026)$ cells at days 3 and 7 , and in LTHSCs $(P<0.014)$ at days 7 and 10. $(C)$ Cell cycle analysis using Ki67 was performed in control mice or mice exposed to IR $7 \mathrm{~d}$ before. The percentage of cells in G0 is plotted. Bars represent mean \pm SEM of three animals per genotype. $\left({ }^{\star}\right)$ The percentage of stem/progenitor cells in G0 was significantly higher in puma ${ }^{+/-}$, puma $^{-/-}$, and p53 when compared with wild-type mice $(P<0.04)$. puma $^{+/-}$, puma ${ }^{-/-}$, or $p 53^{-/-}$animals (Fig. 4C; Supplemental Fig. 8).

\section{Replication stress in stem/progenitor cells is critical} for IR-induced tumor formation

Our data show that, besides depleting thymocytes and mature lymphocytes (data not shown), IR also effectively kills MPP and LSK cells in the bone marrow, forcing surviving LT-HSCs out of dormancy. Hence, loss of Puma may delay tumorigenesis by limiting the compensatory proliferation of stem/progenitor cells that might trigger a replication stress-associated DNA damage response, counterselection, and subsequent genomic instability. Consistently, we observed increasing signs of replication stress-associated DNA damage, as revealed by $\gamma \mathrm{H} 2 \mathrm{AX}$ foci formation, in wild-type but not $\mathrm{puma}^{-/-}$or $\mathrm{p} 53^{-/-}$ stem cells isolated $6 \mathrm{wk}$ after the fourth cycle of irradiation (Fig. 5A,B; Supplemental Fig. 9). This suggests that IR-induced thymic lymphomas arise in wild-type mice presumably due to counterselection against an activated DNA damage response (e.g., by loss of p53) and all of its fatal consequences, as suggested recently (Marusyk et al. 2010). This selection pressure is reduced in puma $a^{-/-}$ mice, translating into delayed tumor formation (Fig. 1C,D). Animals lacking p53 show accelerated tumor formation despite the absence of replication stress, and this can be accounted for by uncontained genomic instability exacerbated by IR damage. Consistently, thymic lymphomas from $p 53^{-/-}$and $p 53$ mutant knock-in mice show frequent aneuploidy (Liu et al. 2004; Morales et al. 2006).

We hypothesized that loss of genomic stability after IR dominates over the protective effect exerted by absent replication stress, caused by the lack of Puma-mediated apoptosis. To test this, we investigated tumor formation in puma $a^{-1-}$ mice also lacking one or both alleles of p53. Spontaneous tumorigenesis caused by loss of one or both alleles of p53 was not altered $(P>0.36)$ on a Pumadeficient background (Fig. 5C). Notably, p53 ${ }^{-/}$puma $^{-/-}$ mice developed IR-induced thymic lymphomas as rapidly as $p 53^{-/-}$mice (Fig. 5D), consistent with our hypothesis. However, in contrast to puma ${ }^{-/-}$mice, puma $^{-/-}$mice lacking one allele of $p 53$ developed thymic lymphomas again (three out of nine), but also a range of other malignancies, while $p 53^{+/-}$mice, able to induce puma, developed exclusively thymic lymphomas (Fig. 5D; Supplemental Table1; Supplemental Fig. 3). Overall, the immunophenotypes of thymic lymphomas arising were similar, suggesting comparable pathology in the genotypes tested (Supplemental Fig. 3C). As reported before (Kemp et al. 1994), all p53+/- thymic lymphomas had lost their wild-type p53 allele, documented by increased levels of ARF protein (Supplemental Fig. 10; Eischen et al. 1999). In the absence of Puma, loss of the second p53 allele was still observed in most lymphomas tested, but disease onset occurred with clearly delayed kinetics (Fig. 5C,D; Supplemental Fig. 10). This demonstrates that stem cell quiescence due to impaired apoptosis of differentiated leukocytes and reduced repopulation demand lowers the impetus for loss of heterozygosity (LOH) of p53, and thereby impairs IR-induced thymic lymphomagenesis. Hence, it would be highly interesting to test for Puma expression levels in Li-Fraumeni syndrome patients in relation to the onset of malignant disease. 


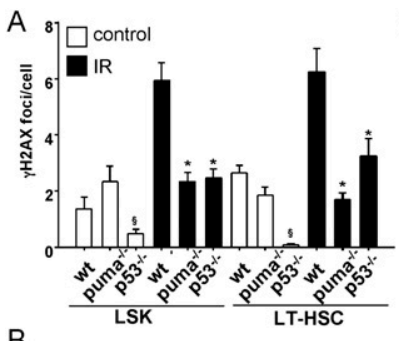

C
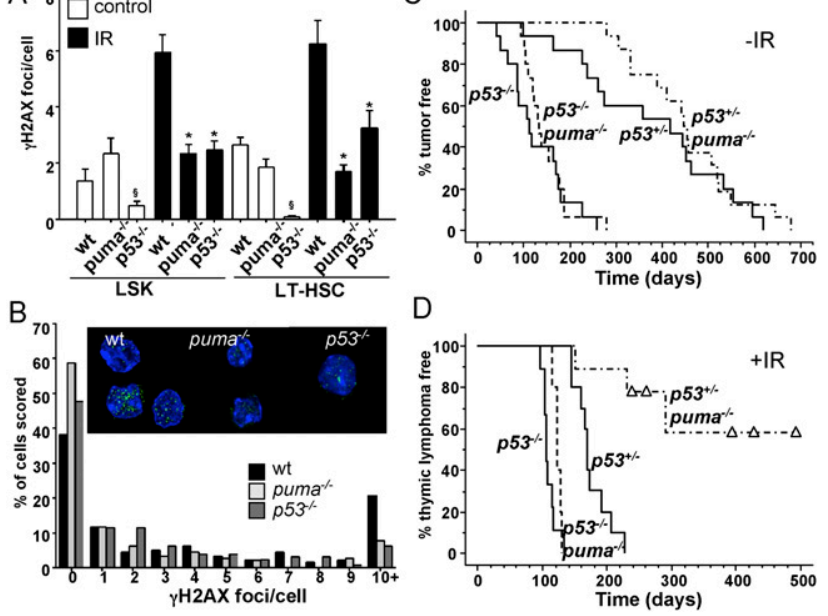

Figure 5. Replication stress-associated DNA damage in wild-type HSCs after IR and restoration of thymic lymphoma development in puma $^{-1-}$ mice by concomitant loss of p53. (A) Quantification of DNA damage foci in LSK cells and LT-HSCs derived from mice of the indicated genotypes. Six weeks after the fourth cycle of IR, stem cells were sorted from the bone marrow onto poly-L-lysine-coated coverslips and stained for $\gamma \mathrm{H} 2 \mathrm{AX}$. (B) Quantification of the percentage of LT-HSCs containing a given number of $\gamma \mathrm{H} 2 \mathrm{AX}$ foci. (Insert) Immunofluorescence detection of $\gamma \mathrm{H} 2 \mathrm{AX}$ foci in LT-HSCs and LSK cells derived from wild-type, $p u m a^{-1-}$, and $p 53^{-/-}$mice $6 \mathrm{wk}$ after the last dose of irradiation. (Green) $\gamma \mathrm{H} 2 \mathrm{AX}$; (blue) DAPI. Images were acquired with a Leica confocal scanning microscope, and the numbers of foci per cell were quantified by using the CellProfiler software, measuring an average of 100 cells per sample from four to six mice per genotype. ${ }^{*}$ ) IR wild type versus puma ${ }^{---}$or $p 53^{-1-}(P<0.001)$. LT-HSCs from untreated $p 53^{-/-}$mice show reduced foci number $(P<0.05)$. (B) Assessment of foci number per cell, in relation to the total number of cells analyzed. Cohorts of $p 53^{+/-}$and $p 53^{-/-}$mice proficient or deficient for puma were monitored for spontaneous tumorigenesis and tumor formation triggered by fractionated IR. $(C, D)$ Kaplan-Meier analysis of tumor-free survival of untreated $p 53^{+-}(n=15), p 53^{-1-}(n=$ 15), $p 53^{+/-}$puma $^{-/-}(n=16)$, and $p 53^{-/-}$puma $^{-/-}(n=15)$ mice $(C)$, or thymic lymphoma-free survival of irradiated $p 53^{+/-}(n=10), p 53^{-/-}$ $(n=9), p 53^{+/}$puma $^{-1-}(n=9)$, and $p 53^{-/-}$puma $^{-1-}(n=5)$ mice $(D)$. Mean survival in days \pm SE: $176 \pm 8$ for $p 53^{+/-}$versus $307 \pm 37$ for p53 ${ }^{+/-}$puma $^{-/-} ; P<0.0001$.

In conclusion, our results demonstrate that maintaining stem/progenitor cell numbers upon DNA damage is required to secure their genomic integrity, and is critical for tumor suppression. Furthermore, our observations support the concept that repeated attrition and regeneration of tissues can contribute to tumor formation, and, during anti-cancer therapy, facilitates the rise of treatment-resistant cancer cells that frequently show increased genomic instability (Allan and Travis 2005). In contrast to related mechanisms discussed in the pathology of liver or gastrointestinal cancer, inflammation appears to be not essential here, as evidenced by normal IR-induced lymphomagenesis in myd88 knockout mice (Michalak et al. 2010).

Finally, while inhibition of Puma may be used to minimize anti-cancer therapy-induced aplasia, mimicking its function by application of "BH3 mimetics" (Labi et al. 2008/-alone or in combination with curative or palliative anti-cancer treatment regimens-may actually increase the risk for developing secondary malignancies; e.g., by killing expanding nonmalignant lymphocytes or their progenitors.

\section{Materials and methods}

\section{Tumorigenesis}

Mice were subjected to four weekly doses of IR with $1.75 \mathrm{~Gy}$ from the age of $4 \mathrm{wk}( \pm 2 \mathrm{~d})$ in a linear accelerator. For the induction of fibrosarcomas, mice were injected i.m. with $1 \mathrm{mg}$ of 3-MC in sesame oil. As a control, mice were injected with vehicle alone.

\section{Flow cytometry, BrdU labeling, pH3, and Ki67 staining}

HSC populations were defined using a biotin-labeled lineage marker flow cytometry kit (e-Bioscience). BrdU was injected i.p. (1 mg per mouse in $200 \mu \mathrm{L}$ of saline) $4 \mathrm{~h}$ prior to sacrifice, or was administered for $12 \mathrm{~d}$ in the drinking water $(0.8 \mathrm{mg} / \mathrm{mL}+1 \%$ glucose $)$. To quantify cells in $\mathrm{S}$ phase, single-cell suspensions were surface-stained prior to flow cytometric analysis using the BrdU-APC flow kit (BD Biosciences). Indirect immunofluorescence staining on ethanol-fixed thymocytes (70\% in PBS) was performed to quantify mitotic cells using an anti-pH3 (Ser10)-specific antibody (Cell Signaling) and goat anti-rabbit Alexa 488 (Invitrogen). Cells in G0 were quantified by cell surface marker staining, followed by fixation in $4 \%$ PFA and permeabilization using $0.05 \%$ Triton-X-100, followed by intracellular FITC-Ki67 (BD Biosciences) and 7AAD staining.

\section{Immunofluorescence}

Staining of $\gamma$-H2AX foci was performed as described (Viale et al. 2009). Images were acquired using a Leica SP5 confocal laser-scanning microscope (Leica Microsystems) with a $63 \times$ glycerol immersion objective, and image analysis was conducted using CellProfiler software.

\section{Statistical analysis}

Statistical analysis was performed by ANOVA or, for comparison of survival of mice and tumor onset, the log-rank (Mantel-Cox) test. Unpaired Student's $t$-test was used to compare differences in proliferation and BrdU incorporation, as well as the number of $\gamma \mathrm{H} 2 \mathrm{AX}$ foci between genotypes. $P$-values of $<0.05$ were considered to be significant.

\section{Acknowledgments}

We are grateful to K. Rossi, C. Soratroi, R. Pfeilschifter, and I. Gaggl for technical assistance; P. Lukas and his team for enabling irradiation experiments; G. Böck for cell sorting; S. Korsmeyer for $b c l-x t g$; and M. Serrano for $p 53^{-/-}$mice. We thank J. Adams and A. Strasser for sharing mice, reagents, and unpublished data. This work was supported by grants from the Austrian Science Fund (FWF): SFB021 to A.V., and P19481-B12 to A.E.; and the TWF to V.L.

\section{References}

Allan JM, Travis LB. 2005. Mechanisms of therapy-related carcinogenesis. Nat Rev Cancer 5: 943-955.

Brathwaite O, Bayona W, Newcomb EW. 1992. p53 mutations in C57BL/6J murine thymic lymphomas induced by $\gamma$-irradiation and N-methylnitrosourea. Cancer Res 52: 3791-3795.

Brugarolas J, Chandrasekaran C, Gordon JI, Beach D, Jacks T, Hannon GJ. 1995. Radiation-induced cell cycle arrest compromised by p21 deficiency. Nature 377: 552-557.

Chao DT, Linette GP, Boise LH, White LS, Thompson CB, Korsmeyer SJ. 1995. Bcl- $\mathrm{x}_{\mathrm{L}}$ and Bcl-2 repress a common pathway of cell death. J Exp Med 182: 821-828.

Egle A, Harris AW, Bouillet P, Cory S. 2004. Bim is a suppressor of Mycinduced mouse B cell leukemia. Proc Nat1 Acad Sci 101: 6164-6169.

Eischen CM, Weber JD, Roussel MF, Sherr CJ, Cleveland JL. 1999. Disruption of the ARF-Mdm2-p53 tumor suppressor pathway in Myc-induced lymphomagenesis. Genes Dev 13: 2658-2669.

Erlacher M, Michalak EM, Kelly PN, Labi V, Niederegger H, Coultas L, Adams JM, Strasser A, Villunger A. 2005. BH3-only proteins Puma and Bim are rate-limiting for g-radiation- and glucocorticoid-induced apoptosis of lymphoid cells in vivo. Blood 106: 4131-4138.

Erlacher M, Labi V, Manzl C, Bock G, Tzankov A, Hacker G, Michalak E, Strasser A, Villunger A. 2006. Puma cooperates with Bim, the 
rate-limiting BH3-only protein in cell death during lymphocyte development, in apoptosis induction. J Exp Med 203: 2939-2951.

Frenzel A, Grespi F, Chmelewskij W, Villunger A. 2009. Bcl2 family proteins in carcinogenesis and the treatment of cancer. Apoptosis 14: 584-596.

Garcia-Cao I, Garcia-Cao M, Martin-Caballero J, Criado LM, Klatt P, Flores JM, Weill JC, Blasco MA, Serrano M. 2002. 'Super p53' mice exhibit enhanced DNA damage response, are tumor resistant and age normally. EMBO I 21: 6225-6235.

Garrison SP, Jeffers JR, Yang C, Nilsson JA, Hall MA, Rehg JE, Yue W, Yu J, Zhang L, Onciu M, et al. 2008. Selection against PUMA gene expression in Myc-driven B-cell lymphomagenesis. Mol Cell Biol 28: 5391-5402.

Kaplan HS, Brown MB. 1952. A quantitative dose-response study of lymphoid-tumor development in irradiated C57 black mice. I Nat1 Cancer Inst 13: 185-208.

Kemp CJ, Wheldon T, Balmain A. 1994. p53-deficient mice are extremely susceptible to radiation-induced tumorigenesis. Nat Genet 8: 66-69.

Kominami R, Niwa O. 2006. Radiation carcinogenesis in mouse thymic lymphomas. Cancer Sci 97: 575-581.

Labi V, Grespi F, Baumgartner F, Villunger A. 2008. Targeting the Bcl2-regulated apoptosis pathway by BH3 mimetics: A breakthrough in anticancer therapy? Cell Death Differ 15: 977-987.

Liao M-J, Van Dyke T. 1999. Critical role for Atm in suppressing V(D)J recombination-driven thymic lymphoma. Genes \& Dev 13: 1246-1250.

Liu G, Parant JM, Lang G, Chau P, Chavez-Reyes A, El-Naggar AK, Multani A, Chang S, Lozano G. 2004. Chromosome stability, in the absence of apoptosis, is critical for suppression of tumorigenesis in Trp53 mutant mice. Nat Genet 36: 63-68.

Macleod KF, Sherry N, Hannon G, Beach D, Tokino T, Kinzler K, Vogelstein B, Jacks T. 1995. p53-dependent and independent expression of p21 during cell growth, differentiation, and DNA damage. Genes Dev 9: 935-944.

Marusyk A, Porter CC, Zaberezhnyy V, DeGregori J. 2010. Irradiation selects for p53-deficient hematopoietic progenitors. PLoS Biol 8: e1000324. doi: 10.1371/journal.pbio.1000324.

Michalak EM, Villunger A, Adams JM, Strasser A. 2008. In several cell types tumor suppressor p53 induces apoptosis largely via Puma but Noxa can contribute. Cell Death Differ 15: 1019-1029.

Michalak EM, Jansen ES, Happo L, Cragg MS, Tai L, Smyth GK, Strasser A, Adams JM, Scott CL. 2009. Puma and to a lesser extent Noxa are suppressors of Myc-induced lymphomagenesis. Cell Death Differ 16: 684-696.

Michalak EM, Vandenberg CJ, Delbridge AR, Wu L, Scott CL, Adams JM, Strasser A. 2010. Apoptosis-promoted tumorigenesis: $\gamma$-Irradiationinduced thymic lymphomagenesis requires Puma-driven leukocyte death. Genes Dev (this issue). doi: 10.1101/gad.1940110.

Morales JC, Franco S, Murphy MM, Bassing CH, Mills KD, Adams MM, Walsh NC, Manis JP, Rassidakis GZ, Alt FW, et al. 2006. 53BP1 and p53 synergize to suppress genomic instability and lymphomagenesis. Proc Natl Acad Sci 103: 3310-3315.

Rossi DJ, Jamieson CH, Weissman IL. 2008. Stems cells and the pathways to aging and cancer. Cell 132: 681-696.

Shao L, Sun Y, Zhang Z, Feng W, Gao Y, Cai Z, Wang ZZ, Look AT, Wu WS. 2010. Deletion of proapoptotic Puma selectively protects hematopoietic stem and progenitor cells against high-dose radiation. Blood 115: 4707-4714.

Viale A, De Franco F, Orleth A, Cambiaghi V, Giuliani V, Bossi D, Ronchini C, Ronzoni S, Muradore I, Monestiroli S, et al. 2009. Cellcycle restriction limits DNA damage and maintains self-renewal of leukaemia stem cells. Nature 457: 51-56.

Vousden KH, Lane DP. 2007. p53 in health and disease. Nat Rev Mol Cell Biol 8: 275-283.

Wilson A, Laurenti E, Oser G, van der Wath RC, Blanco-Bose W, Jaworski M, Offner S, Dunant CF, Eshkind L, Bockamp E, et al. 2008 . Hematopoietic stem cells reversibly switch from dormancy to selfrenewal during homeostasis and repair. Cell 135: 1118-1129.

Wu WS, Heinrichs S, Xu D, Garrison SP, Zambetti GP, Adams JM, Look AT. 2005. Slug antagonizes p53-mediated apoptosis of hematopoietic progenitors by repressing puma. Cell 123: 641-653.

Yu H, Shen H, Yuan Y, Xufeng R, Hu X, Garrison SP, Zhang L, Yu J, Zambetti G, Cheng T. 2010. Deletion of Puma protects hematopoietic stem cells and confers long-term survival in response to high-dose $\gamma$-irradiation. Blood 115: 3472-3480. 


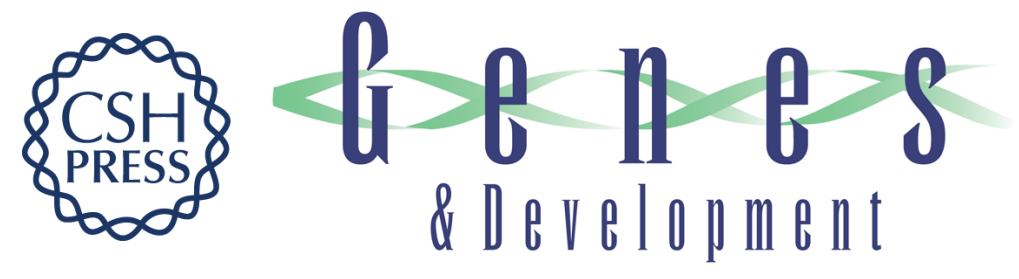

\section{Apoptosis of leukocytes triggered by acute DNA damage promotes lymphoma formation}

Verena Labi, Miriam Erlacher, Gerhard Krumschnabel, et al.

Genes Dev. 2010, 24:

Access the most recent version at doi:10.1101/gad.1940210

\section{Supplemental http://genesdev.cshlp.org/content/suppl/2010/07/26/24.15.1602.DC1 \\ Material}

Related Content Apoptosis-promoted tumorigenesis: ${ }^{3}$-irradiation-induced thymic lymphomagenesis requires Puma-driven leukocyte death

Ewa M. Michalak, Cassandra J. Vandenberg, Alex R.D. Delbridge, et al.

Genes Dev. August , 2010 24: 1608-1613

References This article cites 29 articles, 13 of which can be accessed free at:

http://genesdev.cshlp.org/content/24/15/1602.full.html\#ref-list-1

Articles cited in:

http://genesdev.cshlp.org/content/24/15/1602.full.html\#related-urls

\section{License}

Email Alerting

Service

Receive free email alerts when new articles cite this article - sign up in the box at the top

right corner of the article or click here.

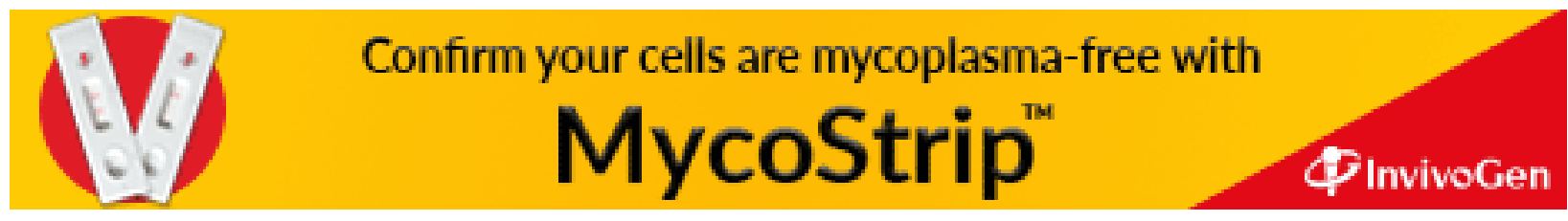

